\title{
Meckel's ileitis versus Crohn's ileitis: diagnosis using balloon enteroscopy
}

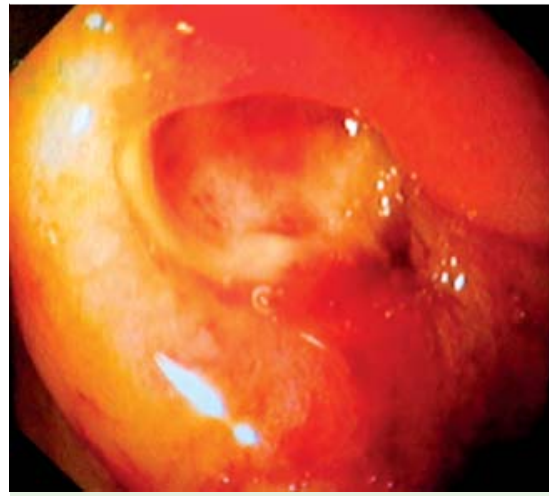

Fig. 1 Enteroscopic view of the ileal lumen in an 18-year-old man who presented with episodic abdominal pain and bloody diarrhea showing an ulcerated diverticulum with some friability at the lower margin.

An 18-year-old man presented with a selflimiting episode of abdominal pain and bloody diarrhea for 5 days. During the following year, he reported similar episodes. We performed a colonoscopy that showed normal colonic mucosa with erythema and a few erosions at the ileum. Histology revealed a nonspecific inflammatory infiltrate in the lamina propria. He was treated with prednisolone with initial symptomatic relief, but was admitted to our hospital 3 weeks later, during prednisolone tapering, because of recurrent symptoms and weight loss of $3 \mathrm{~kg}$. He had been an active smoker since the age of 12 .

Blood tests showed iron deficiency anemia (hemoglobin $9.9 \mathrm{~g} / \mathrm{dL}$ ) and elevated Creactive protein (CRP; $20 \mathrm{mg} / \mathrm{dL}$ ). Immunological assays were negative, including anti-Saccharomyces cerevisiae antibodies. Serum and fecal microbiological assays were negative.

An upper gastrointestinal endoscopy was performed, which was normal, as was the duodenal histology. We decided because of his recurrent symptoms to reappraise the colonic and ileal mucosa. We proceeded to perform a retrograde singleballoon enteroscopy, which showed an ulcerated diverticulum $80 \mathrm{~cm}$ from the ileocecal valve with normal distal ileal mucosa ( $\bullet$ Fig. $\mathbf{1}$ ). The distal margin of the diverticulum was tattooed and biopsied ( $\bullet$ Video 1$)$. Histology showed signs of active chronic inflammation.

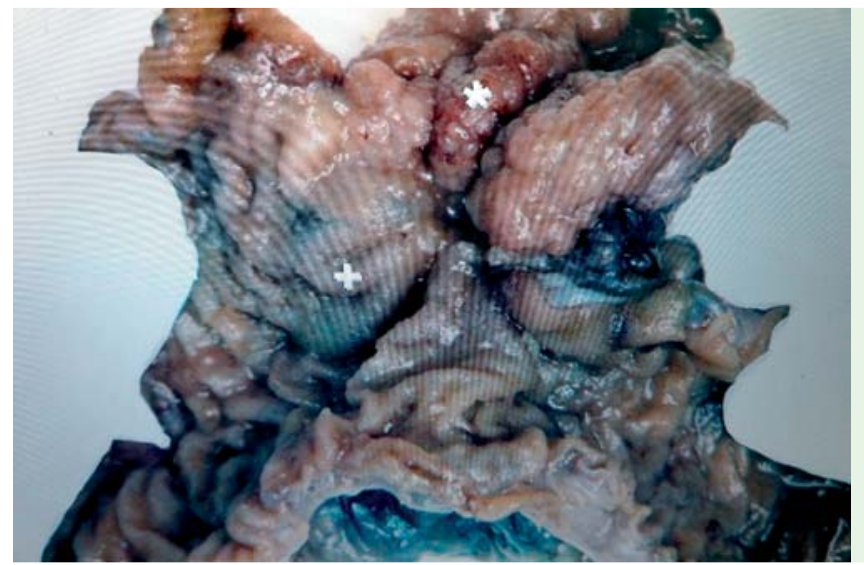

Fig. 2 Photograph of the specimen resected during laparoscopic enterectomy showing the ileal mucosa with circumferential mucosal folds $(+)$ and a Meckel's diverticulum that is predominantly lined by gastric mucosa with rugal folds (*).

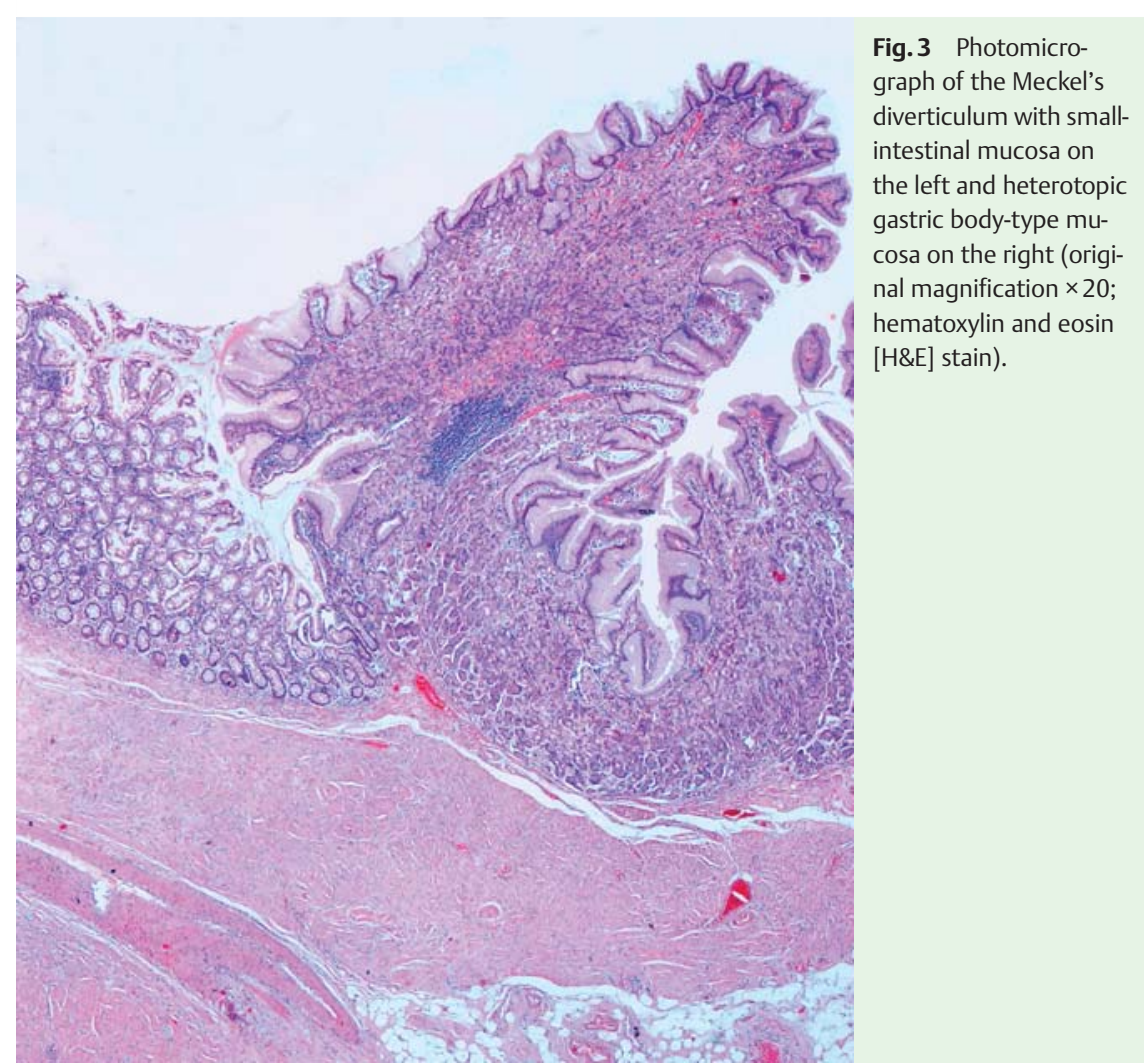

He underwent a laparoscopic enterectomy including the diverticulum 2 weeks later ( $\bullet$ Fig.2). Pathological examination showed gastric mucosa within the diverticulum, thereby confirming the diagnosis of a Meckel's diverticulum ( Fig.3).

At follow-up after 9 months, the patient remained asymptomatic.

Meckel's ileitis is an uncommon manifestation of Meckel's diverticulum [1]. Few other cases have been reported; as in this case, it has usually been a challenging differential diagnosis with Crohn's disease $[2,3]$. In our case, reassessment of the ileal mucosa with balloon enteroscopy was crucial to reaching the correct diagnosis. This

\section{Video 1}

Retrograde single-balloon enteroscopy showing a Meckel's diverticulum. 
technique has been reported as a helpful tool when there is high suspicion of a Meckel's diverticulum, even when technetium pertechnetate scintigraphy is negative [4-6].

\section{Endoscopy_UCTN_Code_CCL_1AC_2AD}

\section{Competing interests: None}

\section{Velosa ${ }^{1,2}$, H. Cardoso ${ }^{1,3}$, E. Rios ${ }^{4}$, G. Macedo ${ }^{1,3}$}

${ }^{1}$ Serviço de Gastrenterologia, Hospital S. João, Porto, Portugal

2 Serviço de Gastrenterologia, Hospital Dr. Nélio Mendonça, Funchal, Madeira, Portugal

${ }^{3}$ Serviço de Gastrenterologia, Faculdade de Medicina da Universidade do Porto, Porto, Portugal

${ }^{4}$ Serviço de Anatomia Patológica, Hospital S. João, Porto, Portugal

\section{References}

1 Feldman M, Friedman LS, Brandt LJ. Sleisinger and Fordtran's Gastrointestinal and Liver Disease. 8th edn. Philadelphia: Saunders Elsevier; 2006: 2075

2 Levesque B, Chua H, Kane S. Meckel's ileitis: not all regional enteritis is Crohn's Disease. Inflamm Bowel Dis 2011; 17: E45

3 Honda K, Mizutani T, Higuchi N et al. A Meckel's diverticulum with an ileal ulcer detected with double-balloon enteroscopy. Endoscopy 2007; 39: E160

4 Uchiyama S, Sannomiya I, Hidaka $H$ et al. Meckel diverticulum diagnosed by doubleballoon enteroscopy and treated laparoscopically: case report and review of the literature. Surg Laparosc Endosc Percutan Tech 2010; 20: $278-280$

5 Huang TY, Liu YC, Lee HS et al. Inverted Meckel's diverticulum mimicking an ulcerated pedunculated polyp: detection by single-balloon enteroscopy. Endoscopy 2011; 43: E244-E245

6 Gasbarrini A, Di Caro S, Mutignani M et al. Double-balloon enteroscopy for diagnosis of a Meckel's diverticulum in a patient with GI bleeding of obscure origin. Gastrointest Endosc 2005; 61: 779-781

\section{Bibliography}

DoI http://dx.doi.org/

10.1055/s-0032-1309851

Endoscopy 2012; 44: E321-E322

(c) Georg Thieme Verlag KG

Stuttgart · New York

ISSN 0013-726X

\section{Corresponding author}

\section{Velosa, MD}

Caminho dos saltos n. 32

Vilas jardins d'agua, moradia $D$ 9050-219, Funchal

Madeira Island

Portugal

Fax: +351-291-572538

mo.velosa@gmail.com 